International Journal of Child, Youth and Family Studies (2012) 1: 20-45

\title{
SEEKING SOLUTIONS WITHOUT CENTERING PROBLEMS: FROM RESEARCH TO PRACTICE
}

\author{
Janet Newbury and Marie Hoskins
}

\begin{abstract}
While it is often a commitment to social justice ideals that bring people to the helping professions as practitioners, our theories and approaches to care are often serviceoriented and expert-driven. Such an orientation to helping often focuses more on individual change - that is, changing those who are experiencing difficulties - than it does on systemic or collective change. The current article offers one very accessible possibility for practitioners who have adolescent clients. By incorporating photo elicitation into the helping relationship, the social nature of "social" problems can be acknowledged and attended to, gently nudging the boundaries of practice in a way that is more contextualized, centering possibilities rather than problems.
\end{abstract}

Keywords: addiction, civic engagement, photovoice, social justice, systemic change, youth

Acknowledgements: We would like to thank David Segal for his contribution to this research process and the reviewers for valuable feedback on the manuscript, and acknowledge the Social Sciences and Humanities Research Council of Canada for funding it.

Address correspondence to: Janet Newbury, C14 Southview RR\#2, Powell River, BC, Canada, V8A 4Z3.

Janet Newbury is a Ph.D. student at the School of Child and Youth Care, University of Victoria, 3800 Finnerty Road, Victoria BC, Canada, V8W 2Y2. E-mail: newburyj@uvic.ca

Marie Hoskins, Ph.D. is Professor and Graduate Advisor at the School of Child and Youth Care, University of Victoria, 3800 Finnerty Road, Victoria BC, Canada, V8W 2 Y2.

E-mail: mhoskins@uvic.ca 
International Journal of Child, Youth and Family Studies (2012) 1: 20-45

Child and Youth Care practitioners and other helping professionals often describe our role as being "supportive” and "therapeutic" (Egan, 2002; Garfat, 2003; Maier, 1991). We depict our approach to help as "relational" and "strength-based" (Gharabaghi, 2008; White, 2007). Our intention is to help individuals and families work through their difficulties in a way that preserves dignity and increases their potential to experience fulfillment and success (Peavy, 2004; Richardson, 2005; Wade, 2007). However, the systems in which such practices occur are still largely service-oriented and expert-driven (Gergen, 1994; Hillman, 1965/1997; McKnight, 1995; Szasz, 2002). Such systems embody assumptions about what need looks like, where agency lies, and how change occurs (DiClemente, 2007; Ellis, 2002; Gergen, 2009). Largely, these implicit assumptions undermine the potential of those seeking help and locate knowledge and power within help providers (McKnight, 1995; Szasz, 2002). In the current discussion, we wish to present an alternative to this dominant discourse about helping by considering a case in point.

This article draws from a study that involved five female participants, all of whom are teenagers or young adults who use crystal meth. While the details of the study and its contribution to learning can be found elsewhere (Newbury \& Hoskins, 2008, 2010), in the current article we wish to focus on the implications for practice. By considering our research in light of the current literature on drug use, photo elicitation, and professional helping practices, how might our study inform addiction services for adolescents?

\section{A Review of the Literature}

\section{Methamphetamine Use}

Methamphetamine use is an area of study in which there is a constantly growing body of literature (see, for example, Bradford, Voorhees, \& Pehl, 2007; Lende, Leonard, Sterke, \& Elifson, 2007; Lambert \& Charles, 2008). By simply logging onto the Internet, we now know what combinations of readily accessible chemicals and substances can be used to manufacture the drug, how it is distributed, and why youth initially begin using it in many cases. We have learned that it is highly addictive and that the damage it can cause to the brain and nervous system is extensive and, in some cases, irreversible. Before the damaging side effects make themselves apparent, crystal meth can contribute to weight loss, lessen anxiety, heighten sex drive, and increase focus, productivity, and concentration, and these "benefits" are often part of the lure for potential users. There is currently a movement toward increasing awareness about the dangers of crystal meth (see Community for Action Against Crystal Meth [CAAMA], 2006; Centre for Addictions Research of British Columbia [Carbc], 2007; British Columbia Mental Health and Addictions Research Network [mhanet], 2007; Partnership for a Drugfree America, 2007). Within this movement, there is a growing emphasis on coordinating efforts among health care professionals, educators, social service providers, law enforcers, educators, and even business owners to work together to combat the problem of crystal meth or, in communities in which it does not yet have a foothold, prevent it from making an appearance (American Academy of Family Physicians, 2007; Australia National Council on Drugs, n.d.; Saul, 2005). 
Thus, the dominant discourse about methamphetamines within the research is one that emphasizes the destruction caused by the substance and efforts towards combatting it. However, there is an alternative discourse, one that is generated by some of those using meth, who may or may not express a desire to give "her" up. In this conversation, her presence is one that is sometimes welcomed, sometimes missed, and sometimes resented, as is evident in online discussions such as those from www.lifeormeth.com. There is a sense of camaraderie among many who engage in this kind of "relationship" discourse, and an understanding that being a "functional user" is a possibility and often a choice (CAAMA, 2006). Lende and colleagues (2007) conducted research on functional methamphetamine use. In their study, they identify the need for a deeper understanding not only of the hazards of the substance, but also of the reasons people continue to use it despite those hazards. They believe that "focusing on functional use, rather than on more global and general 'reasons to use' is a crucial next step in understanding why people continue using drugs” and in developing effective and meaningful supports (p. 466).

While there is an abundance of epidemiological research on drug use among adolescents, there is an identified need for research that looks at substance use as it relates to other aspects of the lives of the people involved, rather than in isolation (Burrell \& Jaffe, 1999; Kwee, 2007; Lambert \& Charles, 2008; Neuhaus, 1993; Truan, 1993). From our review of the literature, we concur with Wilson et al. (2007) that "although risk behaviours are often seen as matters of individual choice, the decision to participate in these behaviours is set within a broader societal context” (p. 243). It is the relationship between individual users and this broader context that is still minimally understood. Carleson, Engebretson, and Chamberlain (2006) contend that "most health intervention programs have been based on theories of social change that target individual behaviour" (p. 837). Truan (1993) states that "efforts for change are blocked by the mainstream of psychological theory, which currently embraces the empirical tradition ... to the exclusion of more contextual, structural causes and solutions” (p. 497).

The high rate of relapse experienced by people who have received addiction support “reveals the importance of innovative ... approaches” (Neuhaus, 1993, n.p.) to addiction treatment. Perhaps by not only conceiving of addiction differently, but also by conceiving of helping differently, we might better fulfill the supportive roles we wish to play in the lives of youth who struggle with addiction.

\section{Photovoice: Methodological Implications for Research}

Rather than relying entirely on interviews, our research involved a photo elicitation process adapted slightly from photovoice (see Newbury \& Hoskins, 2008). Each of our participants was provided a camera, a journal, and some very general questions ${ }^{1}$ around which to

\footnotetext{
${ }^{1}$ For the first two weeks, participants were given two questions to explore through photography and journaling:

"What images represent how I see myself at this point in time?" and "What images represent how I think others see me at this point in time?” Two weeks later, the participants were asked to explore these questions but as they imagine they would answer them five years from now. For more detail please see Newbury and Hoskins (2008).
} 
explore their experiences through photography. We then met with the participants one-on-one, scrolled through their photographs, and dialogued about the ideas they wished to convey through them. Rather than conceiving of this procedure as "data collection", our own social constructionist orientation enabled us to view these dialogues as co-constructive meaningmaking processes (Denzin \& Lincoln, 2000; Gergen, 1994; Kvale, 1996). This means we were less interested in accessing an "objective" truth about their experiences with addiction than we were in understanding how they experience their addictions in context - recognizing that at least for a brief time, our research was also part of their contextual realities. The process took very different routes with each participant; this was valuable in helping us to understand that addiction is experienced in relation to other dimensions of life, including family, friends, identity, media, gender, nature, and relationships (Burrell \& Jaffe, 1999), and must also be responded to as such.

The fact that the inquiry centered images rather than text or discussion is significant. Harper (2000) points out that especially with new technologies, photographs are no longer viewed as objective representations as they once were. Rather, the use of images can provoke reflection that goes beyond the limits of language and invites consideration of the more felt and embodied aspects of life (Leitch, 2006). This enabled the dialogue that occurred later to reach into those more nuanced aspects of experience, deepening the level of inquiry and the learning that could follow, moving beyond that which might have been achieved through direct questioning (Leitch, 2006).

While we stated above that we are working from a social constructionist orientation, this does not in fact represent the theoretical origins of photovoice. We adapted photovoice to function as a research tool, but it is primarily used as a practice to evoke social change (Wang, Morrel-Samuels, Hutchison, Bell, \& Pestronk, 2004). The theoretical basis for this approach comes mainly from Paulo Freire's work on the role of critical consciousness in educational reform in which there is an intentional move from dialectical transfer of knowledge to dialogical (egalitarian) construction of knowledge (Carleson et al., 2006; Freire, 1970). The idea behind photovoice is that every personal story is "mediated by the forms of representation available in a culture” (Wang et al., 2004, p. 911). By addressing social issues photographically through the exploration of personal stories, these deeply nuanced, complex relationships among individuals, cultures, discourses, power (and more) can be addressed. By dialoguing about these relational dynamics in the public realm with policy-makers, for example, concrete social change can occur (Wilson et al., 2007).

While this differs fundamentally from a social constructionist orientation, it is this understanding that personal stories and social realities are not in fact separate that suggests photovoice might also be a valuable therapeutic tool for helping professionals who are attempting to incorporate social justice into the fold of their practices. Rather than locating the onus for change within individuals who are seeking help, photovoice provides a means for practitioners and clients to both see and respond to the complex interconnections between personal struggles and social realities. While helping professionals are increasingly acknowledging there are indeed significant "social determinants of health" (Saul, 2005, p. 6), we 
International Journal of Child, Youth and Family Studies (2012) 1: 20-45

still lack sufficient tools that help us to practice in a way that is congruent with this awareness (Rojano, 2007). Photovoice offers potential as one of these tools.

In order for such a practice to be embraced, however, a reconceptualization of what it means to help is also necessary. Doherty and Carroll (2007) nudge us in this direction with the following observation:

Missing from our discourse is a way to think of ourselves as citizens, not just providers, as people engaged in partnerships with other citizens to tackle public problems. Also missing is the idea of our clients as citizens with something to contribute to their communities ... The provider/consumer dichotomy leaves out a third alternative - citizen partnerships where we are neither providers nor consumers - which our world sorely needs in an era of widespread disengagement from civic life. (p. 225)

\section{Professional Care: Critically Engaging with a Service Orientation to Help}

The above excerpt is a very direct challenge to the common assumption that help is a service to be provided for clients. Indeed, such challenges have come from a multitude of theoretical origins, ranging from Friere (as mentioned above) to Foucault (see below). What these critiques all share in common is a concern with the status quo when it comes to the services available for the least privileged in society. What follows is a brief overview of some of these perspectives.

Moss and Petrie (2002) distinguish services from other provisions, and observe that most commonly the use of the word "service" links to "particular dictionary definitions of 'service' such as 'performance of a function' and 'the checking and (if necessary) repairing and/or replacing of parts' ... to ensure efficient operation” (p. 62). While they acknowledge that the word service can have many meanings, such as "the sense of offering yourself to the other, the performance of a duty or obligation, being of service” (p. 62), it is their sense (and ours) that the term "services" is often associated with the former of the above meanings when it comes to helping professions. McKnight (1995) has long criticized such a service-oriented conceptualization of care. He says:

the political nature of service depends on its association with the unlimited universality of love ... since love is not a political issue, care is not a policy question and service becomes the one business that is an unlimited, unquestionable, and non-political 'good' ... the result is that the politico-economic issues of service care hidden behind the mask of love. (pp. 38-39)

But to what political issues is McKnight is referring? Why does he insist that conceptualizing of care as service provision is inherently political, economic, and problematic?

McKnight (1995) suggests that not only is the service “industry” unsuccessful in solving certain social ills, but it actually perpetuates them with its iatrogenic effect of replacing organic 
community support with professionalized "expertise”. Moss and Petrie (2002) concur by making a case for “children's spaces” as opposed to “children’s services”. They argue that attending to the discourses underlying policies can shed light on why and how practices are constructed as they are. This, in turn, calls into question our taken-for-granted assumptions about what children "need" and makes space for other possibilities.

Over 30 years ago, Roche (1976) posed a similar argument in the context of international development. Grounding his critique in historical events, he challenges the ethnocentrism that supposes the direction of "development" and the folly in assuming that just because certain countries happen to be prosperous, their path should be understood as a model for others. Instead, he suggests, this model of progress has required the subjugation that occurred through colonialism and other international policies in order to bring about that prosperity, and now change must be made that reconsiders the assumption that growth equals progress. The solutions he seeks do not involve providing services for less advantaged populations, but require challenging the systems that have placed them in disadvantaged positions in relation to more affluent nations.

Rose (1998) shares this critique of service-oriented notions of support with an even more cynical view that suggests the intention of the "psy" disciplines is in fact to control, not to help. Tracing the history of psychology in particular, Rose's post-structural analysis of the discourses of helping casts a shadow of doubt over the implications of individualized helping practices. While he understands individual psychologists and psychiatrists might genuinely aim to contribute to the well-being of their clients, Rose suggests that they may, in fact, be further contributing to their imprisonment. Drawing greatly from Foucault, Rose fears that convincing populations to manage their behaviour in socially acceptable ways through the mainstreaming of the psy disciplines and their discourses effectively convinces each and every one of us to police ourselves and each other. As we engage critically with ourselves in terms of our productivity, our relationships, our contributions, and our responsibility, we engage much less critically with those aims in and of themselves. We feel less powerful in the face of political forces and instead turn to our personal lives to exert and experience power, leaving larger systems unchecked.

Szasz (2002), whose position may differ in many ways from some of the theorists above, has also long critiqued service-oriented approaches to care. He argues that diagnosing individuals as either well or not well perpetuates conditions in which help-seekers and professionals must continue to play the respective roles of "afflicted and deliverer" (p. 169). This does nothing to work towards prevention of individual struggles; rather it ensures there will always be another "client" around the corner waiting for assistance. Szasz argues that this individualized approach to care does a more effective job of meeting the "needs" of professionals whose livelihood depends on the existence of clients than it does of meeting the needs of clients themselves.

Hillman (1965/1997) also insists helping is not something that can be done by a profession (with rules and protocol) to a client; rather, it requires individuals to relate honestly and equitably with each other. The particularities of each and every person must be utilized 
through this process, not generalized from and applied universally. This critique of a service orientation to helping is reminiscent of McKnight's (1995) judgement of institutionalized care, where he asserts that:

Service systems can never be reformed so they will "produce" care. Care is the consenting commitment of citizens to one another. Care cannot be produced, provided, managed, organized, administered, or commodified. Care is the only thing a system cannot produce. Every institutionalized effort to replace the real thing is a counterfeit. (p. $\mathrm{x})$

\section{Civic Engagement: A Promising Alternative}

These critics are convincing, and many helping professionals agree with their ideas in theory. But what realistic alternatives exist for those who are seeking support through difficulties, such as adolescents who are struggling with addiction?

Aldarondo (2007) reminds us that most helping professions (including but not limited to family therapy, social work, counselling, and psychiatry) emerged at least in part from a commitment to social justice. That is, from the early days of these professions, "social justice concerns and the will to act on behalf of those at the bottom of the social hierarchy were shared by many of the founding figures” (p. 12). However, as the professions developed and formalized, logistical and other concerns sometimes took center stage. Thus, the ability of these initiatives to reform systems became restricted, all too often leaving the ideals of equity and justice that brought them into being in the shadows of yet another individualized professional helping practice (Aldarondo, 2007).

According to Rojano (2007), these practices have contributed to a great many important changes "within the existing system, when its rules are kept intact” (p. 251). That is, individuals who are struggling have experienced support and success through such interventions. Some systemic changes have also been achieved, but are much more difficult to bring about. They either require the introduction of "new rules into the existing system" (p. 251) or further still, the opportunities for people find ways to step out of the system entirely, equipping themselves with new tools to then join with others and re-enter the system differently, facilitating further changes within it (p. 252).

Such an approach, in the case of addiction, would require moving out of a problemcentered paradigm altogether. By moving beyond the individual (not her problems, and not her as a problem) for a time, she might then be able to shift out of a problem-saturated view of herself and her experience. From this approach, positive change is understood as something that occurs in relation - through civic engagement, or otherwise - not in isolation. Conceived as such, the idea of positive change has the potential to become a reality.

Gergen (1994, 2009) advocates such a reconceptualization of helping practices and change processes. By centering relational dynamics, individuals are no longer required to change 
International Journal of Child, Youth and Family Studies (2012) 1: 20-45

on their own; instead, the dynamics between us demand our attention. This moves us out of blame, but importantly also moves us all into a place of responsibility. From this perspective, all change is social - there simply is no individual (Gergen, 2009). Systemic change that has implications in the lives of individuals requires movement away from an individualized service orientation to help. While it may involve change on the part of individuals, its implications do not stop there and its practices do not necessarily have to start there.

This idea is attractive, but Aldarondo (2007) acknowledges that practitioners rarely have the training to translate such conceptualizations into practice. Our tools are still shaped around service-based notions of help. What is needed, then, are some practical approaches to supporting such change that might in fact bring us back in touch with the social justice orientations that informed the development of our fields in the first place.

\section{Implications for Practice: Photovoice, Addiction, and Change}

The changes articulated in the previous section are reflective of the educational reforms Friere (1970) advocated. This is no coincidence. Those same ideals also informed the practice of photovoice we used in our research. Engaging youth who are addicted to substances through the use of photo elicitation has a number of individual and collective therapeutic implications. It is the implications of photovoice for therapeutic practice, not research (Newbury \& Hoskins, 2008) or social change (Wang et al., 2004), to which we will turn for the remainder of this paper. In the following sections, then, we will draw from the (a) research findings to inform a (b) discussion of (c) implications for practice, rather than addressing each of these aspects of the study as if they are distinct.

Before launching in, however, we want to make clear two important points. First, we recognize that great efforts towards more contextualized practice already exist among the various helping professions. As mentioned previously, Aldarondo (2007) highlights a number of these efforts. Nature-based programs also serve to highlight the connectedness of individuals with their surroundings (human and otherwise) in an effort to work towards solutions without locating problems within help-seekers (Taylor, Segal, \& Harper, 2010). Performance-based group work is another widely used approach to constructively responding to struggles without individualizing them (Lee \& de Finney, 2004). Similarly, a number of narrative approaches are also used in this way (Denborough, 2008). We simply offer photovoice as one fruitful possibility among many, in order to increase the number of resources from which practitioners can draw.

Secondly, we are not suggesting an emphasis on social engagement as a replacement for consideration of individual experiences. On the contrary, it is by acknowledging their social embeddedness that individual struggles can more effectively and respectfully be addressed (Gergen, 2009). In this way, we do not wish to eliminate one-on-one intervention; we offer this as an avenue through which such helping relationships may be fostered. Our concern is not with whether one-on-one interventions should take place, but rather how they occur. Perhaps by putting more emphasis on social dynamics within helping relationships, it will become clear that 
it is not a matter of choosing to focus on individual or social struggles, but recognizing the interrelatedness of both.

With that, we will share some of the potential for practice we have gleaned from our research in which photovoice was used.

\section{Engaging “in the moment"}

First, and perhaps most obviously, utilizing visual methods in therapy with adolescent participants can be beneficial in that "it is closely related to the medium of video/television, which is an integral and accepted part of young adults' terrain. As a consequence, the method has an appeal that can be readily 'tapped into' ...” (Riley \& Manias, 2004, p. 399). As Child and Youth Care (CYC) practitioners and others who work with young people can attest, engaging in a way that resonates for young clients can sometimes be the biggest challenge to establishing a meaningful connection (Hoskins, 1999; Lee \& de Finney, 2004). Moreover, such a connection is often seen as critical to any kind of helping relationship (Garfat, 2003). In our research, the use of digital cameras proved an effective tool for doing just this, as the girls who participated in our project were very comfortable with the medium. Not only that, but the act of working through something together, while having something relatively benign and impersonal between us (that being a computer screen), enabled the conversations to flow easily. Sitting side by side rather than face to face, and focusing our attention on the screen rather than each other, made the conversation feel much less strained as well.

A great deal of practice and research with youth supports the idea that engaging in a task together is a therapeutic way of developing strengths and working through difficulties (Garfat, 2003; Krueger, 1994; Lee \& de Finney, 2004). Several of our research participants articulated that they experienced therapeutic value in the photovoice process. For example, when Beth ${ }^{2}$ was asked halfway through the first research conversation how she was feeling she said, "It's going pretty good. This is the first opportunity I've had in a long time to say what I think.” Thus, photovoice can serve as one tool by which practitioners can engage relationally with youth in a therapeutic process. This, however, still leaves us within the realm of individual change, albeit relationally facilitated.

\section{Depth and quality of dialogue}

Because the conversations center the photographs rather than the participants, the dialogue that occurs can move to a place in which nuance and contradictions can be explored without defensiveness, which is an important aspect of the helping practices in which alternative possibilities are intentionally being sought. Together with the researcher, the participants can unpack some of the ideas that emerge through the images and the metaphors they employ. As

\footnotetext{
${ }^{2}$ Names have been changed to protect confidentiality and anonymity of participants.
} 
International Journal of Child, Youth and Family Studies (2012) 1: 20-45

explained by Wilson and colleagues (2007), "in photovoice, participants represent their world with their own photographs, which they then analyze to surface their meaning” (p. 242).

The following image (Figure I) and excerpts demonstrate how this process evolved with one of our participants:

Figure I (puddle)

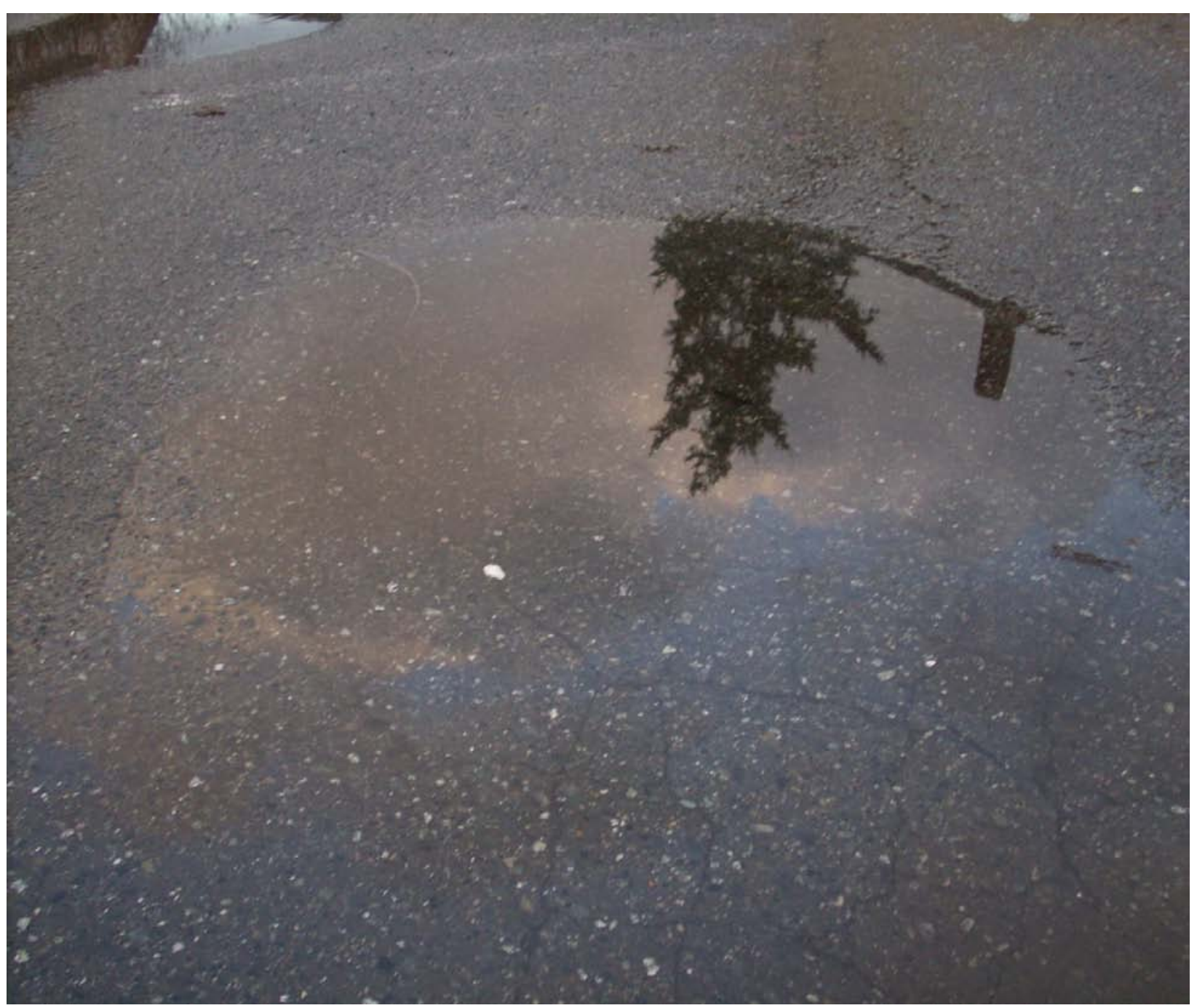

Beth: This picture of the puddle with the reflection of the tree in it and the sky, I think it's more about the second question, what images represent what other people think I am at this point in my life. A lot of people have told me lately that they are reminded of themselves when they look 
International Journal of Child, Youth and Family Studies (2012) 1: 20-45

at me, I'm a reflection of themselves ... I think they're seeing intelligence but struggle, like struggling from the past that's still living life day to day and for the future. of life:

Later in the conversation, she comes back to this image in relation to some complexities

Beth: The picture of the tree is life. In that picture there is life. And it's overcast, right? It's still gloomy, but that tree is in there, there is still life ... I believe I am a reflection of life. ... It doesn't mean that I am the way of life or anything; I am another thing that represents life.

And later still she returns to this image again, when discussing her changing understanding of her place in the world in relation to others:

Beth: I remember stomping through puddles when I was a little kid, and now that I am older I try to walk around them because you do not want your feet getting wet ... That little puddle has a life; it has feelings ... People do not even notice that they are right there and they just walk right through. And the whole stomping through the puddle, like, and being walked on and everythingwhen people do realize that you are there, you know, it feels like that is all they want to do, like stomp on you and walk all over you.

David: So, when someone realizes that you are right there in front of you, they have this desire to want to stomp on you?

Beth: Yeah, and walk on you, and kind of abuse you, 'cause you know how I just made that little joke about puddles having feelings, you know kids want to go and stomp through the puddles, not meaning that kids are out to get me.

Those who use photovoice as a tool for social change recognize that "photovoice helps people to use visual evidence to recognize and voice their problems and potential solutions" (Walter Goodhart et al., 2006, p. 52). By moving beyond the literal and perhaps more obvious interpretations of events, a process such as photovoice invites critical thinking that enables a number of contextual elements to be incorporated into interpretations, as evidenced by the example above. With one image of a reflection of a tree in a puddle, Beth was able to explore her relationships to other people, her understandings of how she is perceived, how this in part informs her identity, and even very general conceptualizations of life and her place in it. By making room for unstructured critical thinking, the conversation can eventually move to her own agency within such complex dynamics, her values, and the choices she has the capacity to make within it all.

\section{More than "couch talk"}

Photovoice provokes generative dialogue, but it also has the potential to do more than that. For another participant, Karen, the introduction of photography into her life provided an alternative that did not previously exist. As the following image (Figure II) and excerpt 
International Journal of Child, Youth and Family Studies (2012) 1: 20-45

demonstrate, photography has opened doors for her not only creatively, but even in terms of the role she plays in the world. Photovoice is part of a process through which she is beginning to redefine herself from addict to citizen. In this way, it is a tool that can promote change "within the existing system” (Rojano, 2007, p. 251).

Figure II (Fire hydrant)

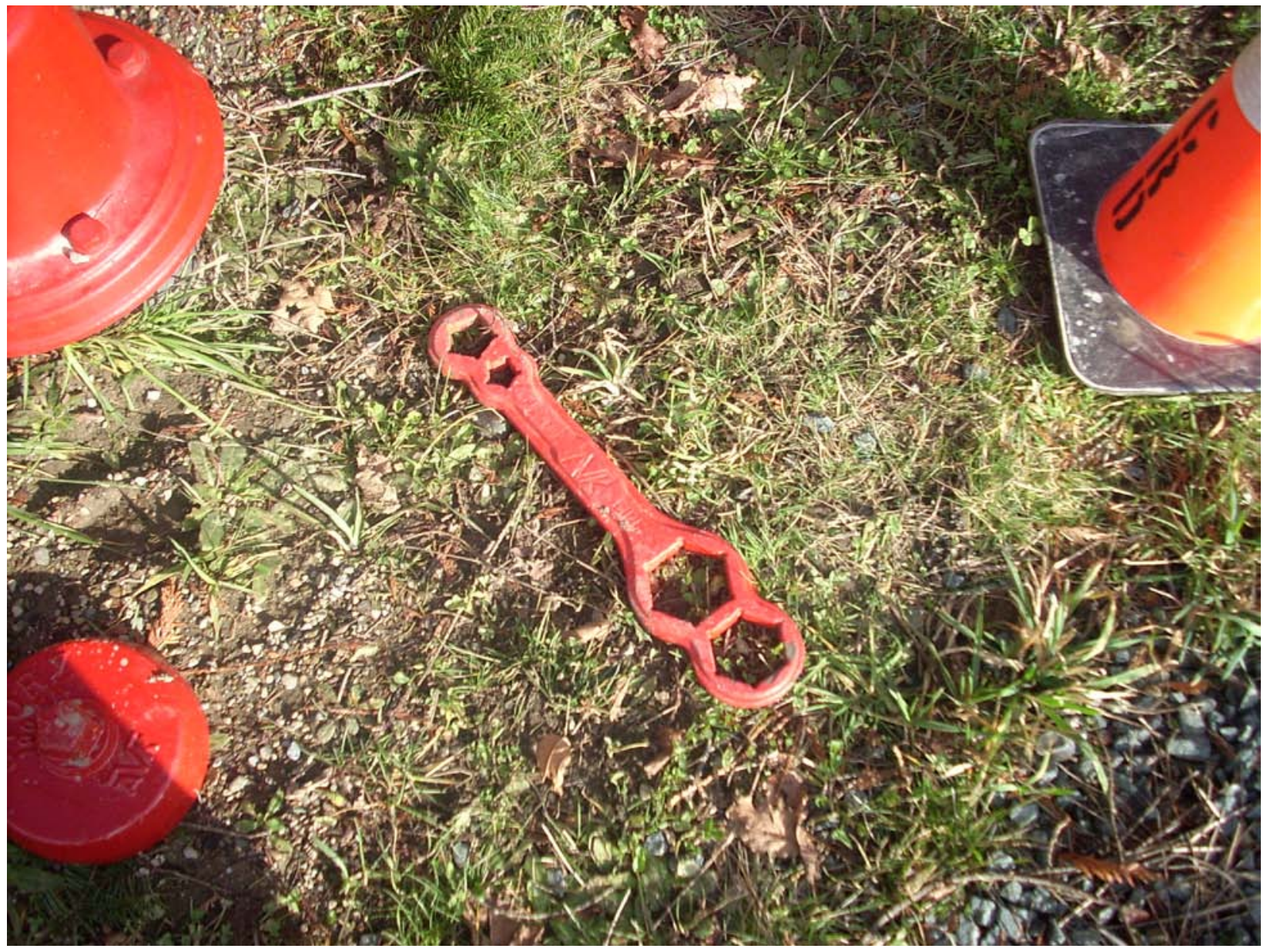

Karen: And some person left the - you know those cranks to take the front of the fire hydrants off. Someone left one of those right there and I was like, “Man, you guys are lucky I don't still do 
International Journal of Child, Youth and Family Studies (2012) 1: 20-45

drugs or I would have taken that and like caused some shit, man." But I didn't. I just left it there and took a picture of it instead.

This is not to say, of course, that a love of photography itself is necessary in order for photovoice to be a valuable therapeutic tool for youth who use certain substances. Nor do we intend to suggest that that photography itself simply serves as a diversion from the impact of such use. But for this participant, her participation in photovoice provoked an exploration about what she deems important and how she can live in accordance with these priorities. She discovered throughout the course of the photovoice project that her previous choices were not in alignment with her overall values. This discovery did not occur in isolation, but was a process that developed alongside other initiatives she was taking at that time towards recovery from her crystal meth use. By understanding photovoice as a tool that can facilitate such developments rather than a singular answer, practitioners may be able to support youth in working towards their own solutions.

Another example (Figure III) provided by the same participant illustrates again how the photovoice process provoked her both to think differently and (importantly) to act differently. Here she explains a situation that occurred between our first and second interviews in which she chose photography over drug use:

Figure III (Skate park) 


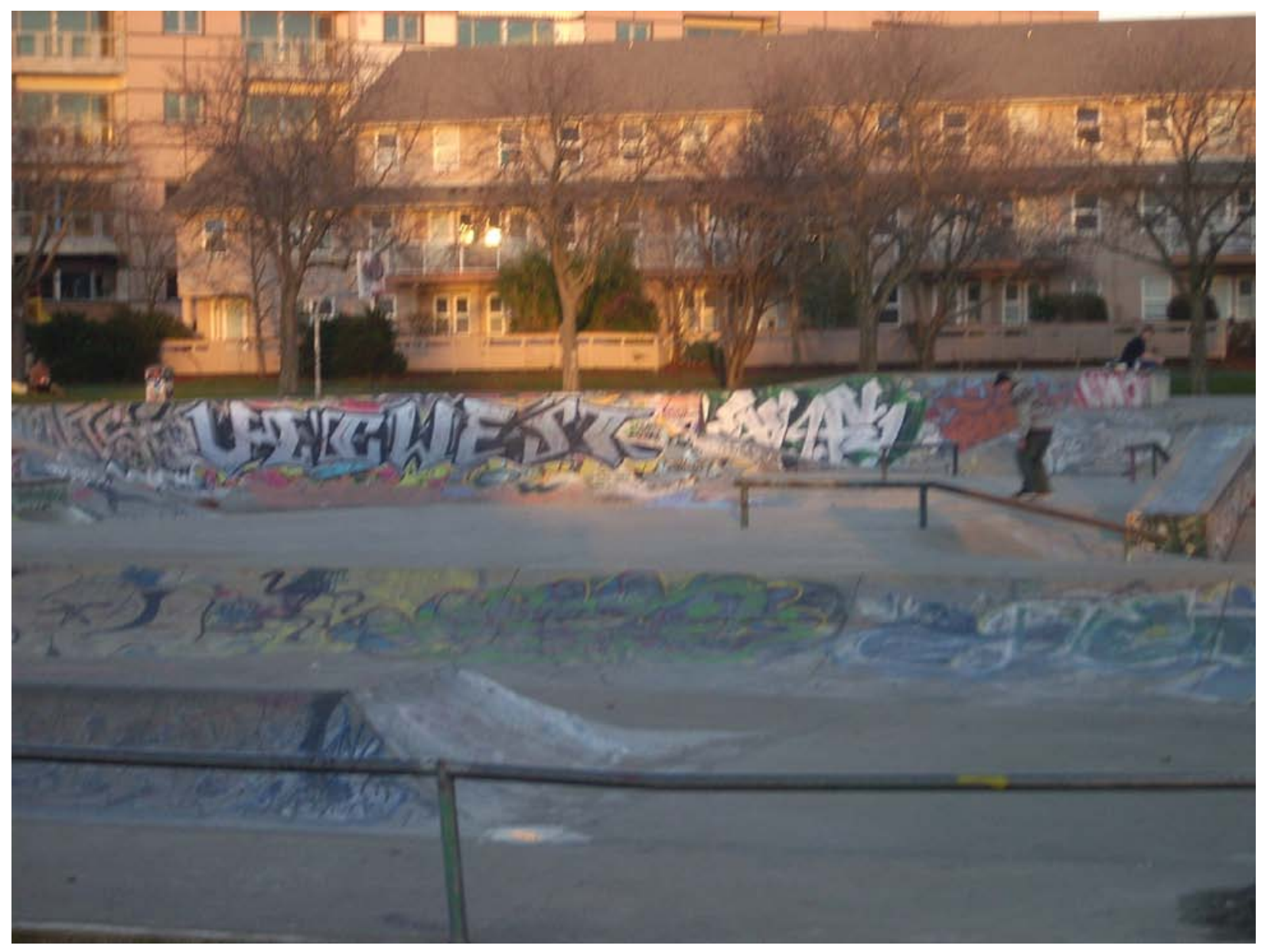

Karen: Um, this is actually interesting here. We were on our way to get drugs and then I changed my mind.

Janet: Really? Why did you change your mind?

Karen: 'Cause I just decided I don't want to. I saw all the graffiti here and I just thought, "You know what? I'd rather take pictures of this graffiti here than like go get drugs." And she [friend] was like, "Yeah?" And I was like, "Actually I don't want to do drugs. I'm going to call my mom." And I called my mom and she came and picked me up ... Also, it was after I ran into these people too [shows me a picture of some old friends] ... And they were like, "Oh, you look so good. I'm glad you're doing so good!" ... And I called my mom and we went out for dinner.

As is made clear with the above example, Karen's choice not to use drugs that day was not an entirely self-driven decision. It was made possible in part because there was a camera in her purse and she had been recently enjoying photography, in part because she knew her mom was available to come and get her, and in part because her friends had complimented her 
progress, strengthening her newly developing identity as "clean”. Experienced together, all of these relational dynamics contribute to her recovery process, and none of them center her "problem" of drug use. This leads us to the next reason photovoice may be a valuable resource for practitioners who are supporting youth who engage in problematic substance use.

\section{Connecting individual struggles with social realities}

As was described earlier, helping professionals across various fields have been working hard to incorporate social justice ideals into clinical practice (Aldarondo, 2007; Denzin \& Giardina, 2009; Newbury, 2010; Reynolds, 2002). Within public health in general there is an increased awareness that "concepts that inform philosophical and theoretical approaches have been based on ... theories of social change that target individual behaviour" (Carleson et al., 2006, p. 837). Focusing interventions on the individuals who are seeking support, requiring that they alone change can serve to further marginalize people who are already living in the margins (Reynolds, 2002). Within the social services in particular, the importance of acknowledging the social nature of individual struggles is increasingly recognized (Coates \& Wade, 2007; Reynolds, 2002). Viewing individuals in isolation from their political and social contexts is not only potentially ineffective in working through difficulties, but according to Clarke (2005) it is based on a fallacy. Individuals do not exist in isolation, and a situation is comprised of many human, non-human, and relational dimensions which all must be taken into consideration when aiming to change a given situation.

Gergen (2009) affirms this position by suggesting that understanding an experience and working towards a resolution does not involve developing an objective picture of reality and then fixing it. Rather, it involves recognizing there is no objective picture of reality; it is everchanging due to its fluid nature and the fact that none of us approach a situation with the same set of experiences (i.e., knowledge), nor from the same vantage point. Thus, from this perspective, supporting someone in a difficulty such as addiction requires finding a way to move through the dynamic matrix of elements comfortably, not presenting them with objective answers that make sense to someone else's "expert" reality (Szasz, 2002). This brings us finally to a more systemic approach to change - change that requires movement not only on the part of "clients", but also on the part of helping practitioners. In other words, this brings us to citizen partnerships (Aldarondo, 2007).

In order to avoid individualizing a struggle such as addiction, but still supporting clients to recognize and utilize what agency they have within their particular contexts, practitioners need tools that enable clients to connect their struggles with their social realities. They need to find ways that move beyond the readily available techniques and strategies that - even unwittingly locate problems and solutions inside their individual clients. Embodied knowing, performance, and emotion have the capacity to move us beyond what already is, towards new possibilities (Denzin \& Giardina, 2009). Photovoice is a very concrete, practical tool that can help practitioners and clients tap into such possibilities together. 
How exactly might photovoice facilitate this process for adolescents who are addicted to substances, and what implications might that have for next steps within their therapeutic process? Throughout the conversations we had with our research participants, there are a great many examples as to how this may occur. Allowing it to unfold differently for each participant is a crucial aspect of any therapeutic endeavour (Hoskins \& Artz, 2004). Perhaps an example can help illustrate the value of photovoice in connecting individual struggles with social realities. The following series of images (Figures IV through VI) were shared by Meghan, a young woman who used crystal meth for many years and had been "clean" for almost one year prior to participating in our project. Through images, reflection, and dialogue, she was able to convey how her experience of addiction is very much enmeshed with her world in general and cannot be tackled in isolation:

Figure IV (Globe in colour)

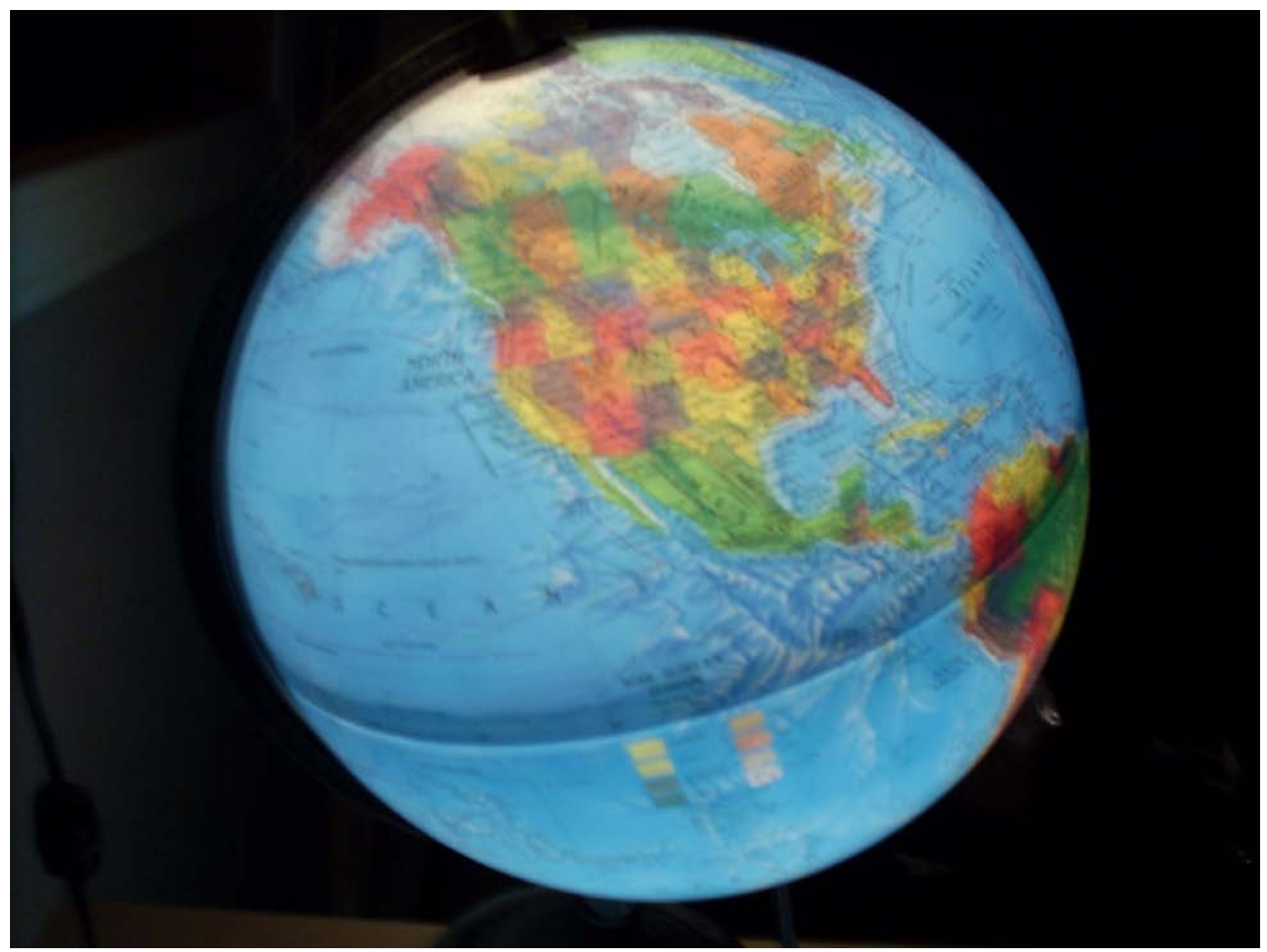


International Journal of Child, Youth and Family Studies (2012) 1: 20-45

Meghan: I know the world's a big place but, um, I think I can - if I can conquer the whole thing with crystal meth I think I can take on the whole world. Sometimes I feel like that.

Janet: That is so amazing. So do you feel like you've already taken steps towards that?

Meghan: Um, probably in the last year, less than the last year. Probably the last six months maybe, that I've started feeling like I have more control over everything.

Janet: What changed for you?

Meghan: I have no idea ... But when I got my full-time job, 'cause I was only working a part-time job, and I started paying rent on my own and everything ...

Janet: When you applied for the job - the full-time job - did you feel like, "Yeah, I can do this"?

Meghan: Um, yeah, I had been wanting to apply for a job but my roommate's dad had kind of found out they were hiring there, and he told me about that ...

Janet: So you had a lot of people behind you who believed you could do it? Like your roommate's dad?

Meghan: Yeah, oh yeah. It helps when people are pushing you and telling you you can do it. Yeah, definitely.

Janet: Was there a time when you didn't?

Meghan: Um yeah. When I was really into drugs and stuff I didn't really hang around anyone that was really caring about what I was doing.

Janet: I wonder what led you into surrounding yourself with people who believed in you again?

Meghan: I don't know. Tired of doing what I was doing maybe. Tired of - I don't know. I think it was a lot to do with my boyfriend, 'cause I never, I didn't take care of myself. I really didn't care about taking care of myself or what I looked like or how healthy or unhealthy I was until I started going out with him. And he was kind of reminding me, he reminded me, you know, life is a lot better when you actually care about yourself. 
International Journal of Child, Youth and Family Studies (2012) 1: 20-45

Figure V (Globe black and white)

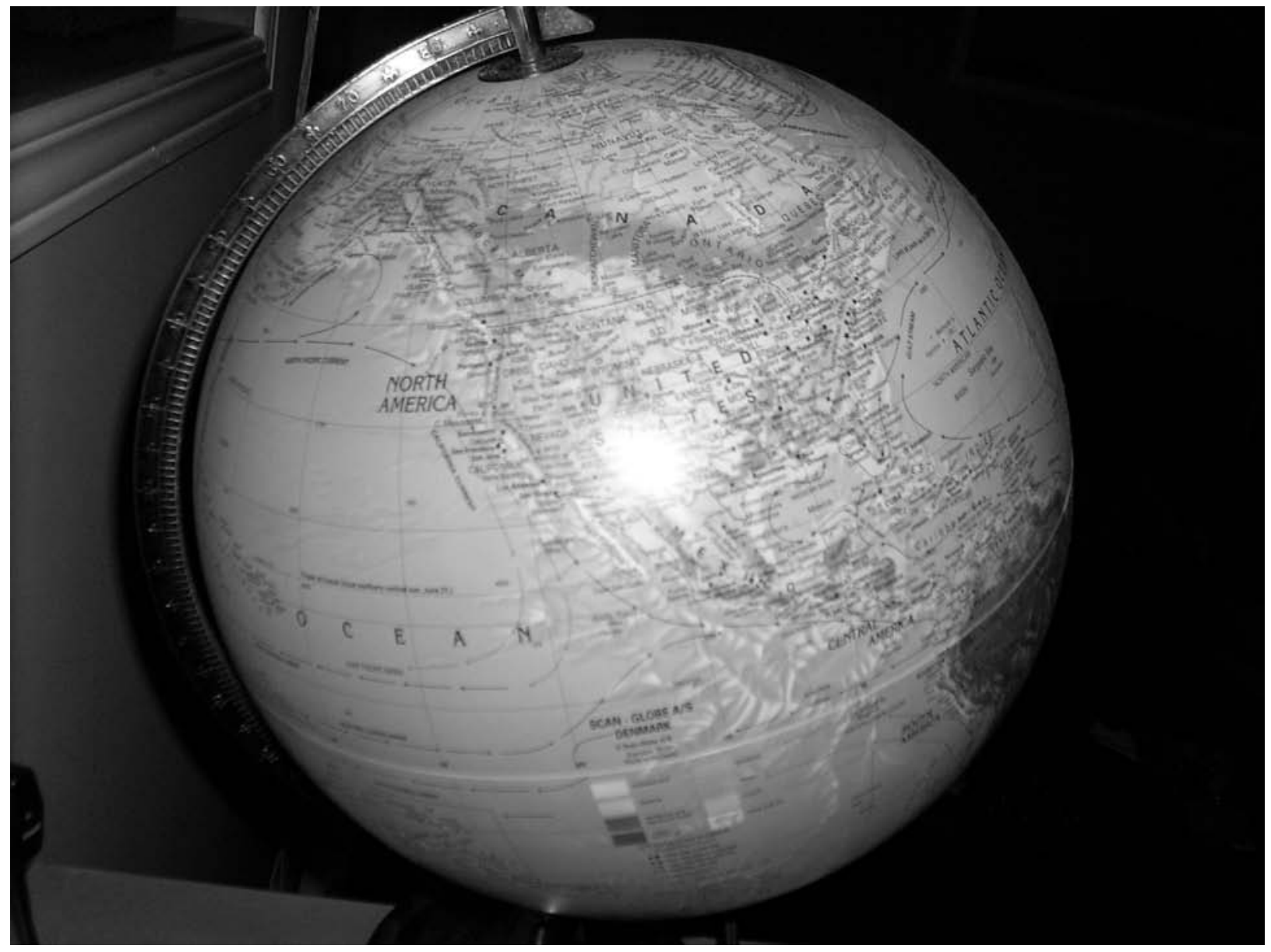

Meghan: The black and white one I thought it made it feel more like when I'm trying to do things and it doesn't really work. Like when I kind of get pushed back. 
International Journal of Child, Youth and Family Studies (2012) 1: 20-45

Figure VI (Globe shaky)

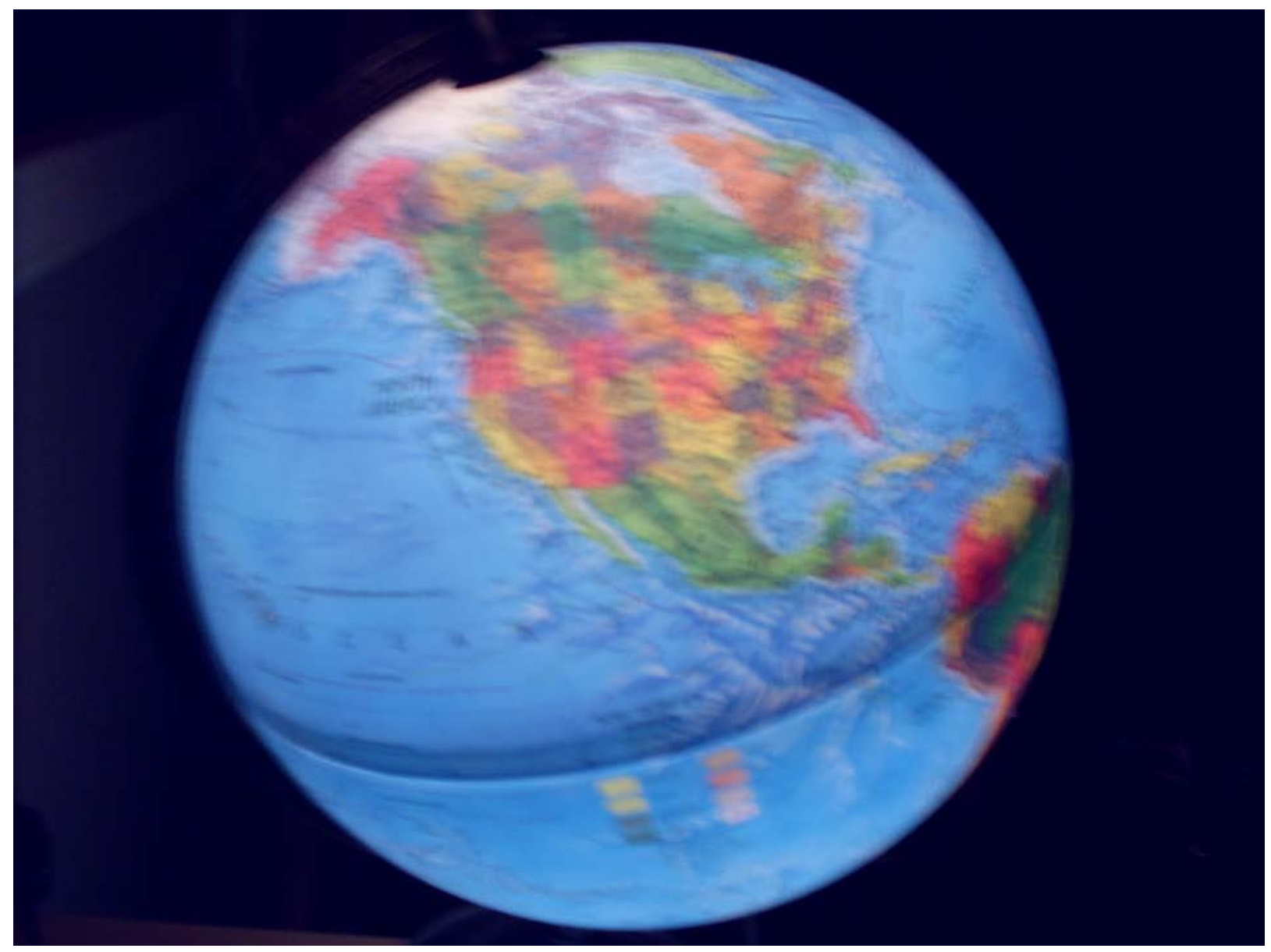

Meghan: That one's when I'm angry, and feeling really angry at the whole world more than anything.

Janet: So what would be a situation that brings out this feeling in you now?

Meghan: Partly when I'm, like, wanting to smoke, craving to smoke crystal meth, 'cause I get those sometimes. And I'm just pissed off at everything and everything just pisses me off so I just want to forget about it all but I know I can't ... I get mad at my mom and everything. My mom can get - she thinks she's helping and she's just pissing me off more by getting a little bit too "mom-like" I guess. I don't know what you call it but yeah, things piss me off. Or I get sort of there are situations where I don't have enough money. Like my rent cheque almost bounced or something but doesn't but I get myself all into this huge fluster or mess and I'm running around. 
That's when I'm really angry. Sometimes I feel like it's just easier not doing anything legitimately or anything, but it is.

The above series of images and excerpts illustrate the complex interplay between her individual struggles with addiction and the world around her. They also demonstrate how her experiences with addiction can be either exacerbated or alleviated in part by the people around her. However, her agency in strategically selecting who to surround herself with depending on what she feels she needs is also made evident above. Through photovoice, Meghan was very effectively able to share the fact that she clearly does not experience addiction as an individual phenomenon. Therefore, as helping professionals, it does not make sense to respond to it as such.

This does not only mean recognizing the myriad of contextual elements that inform the circumstances these girls are experiencing. Such a perspective does not honour the agency demonstrated above by Meghan. Responding to addiction contextually also means recognizing that recovery itself requires engaging contextually. Social justice, then, does not only mean supporting those who are less privileged. Social justice requires providing spaces for those who are struggling to be civically engaged, that is focusing not only inward during their recovery process, but also outward. As cited in Rojano (2007), "Putnam (2000) found a strong correlation between social engagement and wellness” (p. 257). Rojano goes on to say that with civic engagement, the opportunity exists to for clients to move

away from a position of isolation and victimization, the person is now an empowered and committed community member. Shifting from the passive role of user or recipient of the services and the good will of others, the person becomes the helper and provider of assistance to others. (p. 258)

Towards this end, photovoice generally involves direct dialogue with policy-makers on the part of participants (Carleson et al., 2006; Wang et al., 2004). This was not the case for our research process, but our participants shared with us a sense of satisfaction that by engaging in research, they hope to be indirectly contributing to the recovery of others addicted to crystal meth. For most of them, this was their primary reason for choosing to do the project. Some of them were also socially engaged in other ways: Several gave presentations in local high schools about drug addiction; one even wrote an article for a local paper. Another participant is passionately involved in environmental activism which she claimed ultimately provides her with the drive to overcome her addiction. As evidenced by these commitments, addiction is not something these girls need to control in order to engage socially. Perhaps it is precisely the opposite: Their desire to engage in the world may enable them to more readily overcome their addictions.

By attending to such dynamics as practitioners, rather than insisting on centering problems when our clients are striving not to, perhaps we can contribute to both individual and systemic change. Rojano (2007) reminds us that the present therapeutic expectation that clients "take control over their lives" does not take into account the fact that social inequities do not provide us all with the same opportunities to do so all of the time (p. 257). A more socially 
International Journal of Child, Youth and Family Studies (2012) 1: 20-45

conscious approach to therapeutic practice, which invites those who are struggling to engage socially, could disrupt such dynamics greatly.

\section{Conclusion: Photovoice, Change Processes, and Clinical Practice}

While photovoice can take place one-to-one, it is active, engaged, critical, and necessarily contextualized. Thus, it can be a valuable tool for those practitioners who wish to incorporate social justice ideals into their clinical practice. Clearly, photography alone is not sufficient to overcome addiction. But that is not the argument of this piece. Used as one tool among several used by practitioners who work with adolescents, it can disperse the onus for change beyond the individual, to address multiple aspects of the experience being explored, and to follow the lead of clients as to where the most time is spent. Indeed, as the examples above indicate, it can even provide opportunities for some spontaneous encounters in which the clients will find themselves responding differently to their situations. The likelihood that engaging in photovoice will also provoke different kinds of interactions and conversations for clients outside of the clinical relationship - with friends and family, for instance - is certainly high, as most of our participants expressed a desire to share their photographs and reflections with others in their lives. This moves the "real" work out of the hands of practitioners, and into the hands of the clients themselves. As Freire (1970) asserted years ago, the goal is "to engage the people to participate in their own learning, a combination of action and reflection that he called praxis" (Carleson et al., 2006, p. 838). And this aspect of the work can be considered a step in the direction of more socially just practice.

Nakkula and Ravitch (1998) remind us that it is not only clients who need to change. Enough research has been conducted already to make clear that approaches to helping must also be adjusted at this point. They state:

Although the concept of mutual transformation through meaningful engagement with clients, including children and youth, may sound reasonable, exciting, or even obvious, therapeutic models tend to look almost exclusively at client change ... Most of us in the broader counselling and development field view ourselves as caregivers, not as recipients of or participants in a change process. (p. 86)

In order to move beyond the dominant individualistic, service orientation to helping, we need effective tools that can support clients without further pathologizing them. We need to be willing to challenge our own notions of what that looks like, and how it is likely to occur. Photovoice is one such tool that can move us in this direction. While it does not occur entirely outside of individualized interventions, "it is in the collision of traditions that innovation is born" (Gergen, 2009, p. 94). This tool provides practitioners with a way to work relationally with clients, to encourage clients to critically reflect on their social realities, and to support them in moving beyond merely thinking differently, to acting differently in a way that does not turn them into the problem they are facing. And this, in turn, may bring us one step closer to socially just practice by encouraging us, too, to embrace change in the ways we are conceptualizing and enacting support. 
International Journal of Child, Youth and Family Studies (2012) 1: 20-45

\section{References}

Aldarondo, E. (Ed.). (2007). Advancing social justice through clinical practice. Mahwah, NJ: Lawrence Erlbaum Associates, Publishers.

American Academy of Family Physicians. (2007). Meth abuse: What you should know: Information from your family doctor. [online] Retrieved November 12, 2007, from www.aafp.org/afp

Australia National Council on Drugs. (n.d.). Methamphetamines (Position paper). [online] Canberra, ACT. Retrieved June 29, 2007, from http://www.ancd.org.au/publications/pdf/pp_methamphetamines.pdf

British Columbia Mental Health and Addictions Research Network (mhanet). (2007). [online] Retrieved November 10, 2007, from www.mhanet.ca

Bradford, W., Voorhees, K., \& Pehl, K. (2007). Methamphetamine abuse. American Academy of Family Physicians, 76(8), 1169-1176.

Burrell, M., \& Jaffe, A. (1999). Personal meaning, drug use, and addiction: An evolutionary constructivist perspective. Journal of Constructivist Psychology, 12(1), 41-63.

Carleson, E., Engebretson, J., \& Chamberlain, R. (2006). Photovoice as a social process of critical consciousness. Qualitative Health Research, 16(6), 836-852.

Centre for Addictions Research of British Columbia (Carbc). (2007). Victoria, BC: University of Victoria [online]. Retrieved November 10, 2007, from www.carbc.ca

Clarke, A. (2005). Situational analysis: Grounded theory after the postmodern turn. Thousand Oaks, CA: Sage Publications.

Coates, L., \& Wade, A. (2007). Language and violence: Analysis of four discursive operations. Journal of Family Violence, 22(5), 511-522.

Community for Action Against Crystal Meth (CAAMA). (2006). "Life or meth" discussion board [online]. Retrieved June 25, 2007, from www.lifeormeth.com

Denborough, D. (2008). Collective narrative practice: Responding to individuals, groups, and communities who have experienced trauma. Adelaide, Australia: Dulwich Centre Publications.

Denzin, N., \& Giardina, M. (Eds.). (2009). Qualitative inquiry and social justice. Walnut Creek, CA: Left Coast Press. 
International Journal of Child, Youth and Family Studies (2012) 1: 20-45

Denzin, N., \& Lincoln, Y. (Eds.). (2000). Handbook of qualitative research (2nd. ed.). Thousand Oaks, CA: SAGE.

DiClemente, C. (2007). Self-regulation, motivation, and the process of change. Presented at Changing behaviour, changing lives: Alcohol and co-occurring conditions, conference of the BC Mental Health and Addictions Research Network, Vancouver, BC.

Doherty, W., \& Carroll, J. (2007). Families and therapists as citizens: The families and democracy project. In E. Aldarondo (Ed.), Advancing social justice through clinical practice (pp. 225-244). Mahwah, NJ: Lawrence Erlbaum Associates, Publishers.

Egan, G. (2002). The skilled helper: A problem-management and opportunity-development approach to helping (7th ed.). Pacific Grove, CA: Wadsworth Group.

Ellis, C. (2002). Being real: moving inward toward social change. Qualitative Studies in Education, 15(4), 399-406.

Freire, P. (1970). Pedagogy of the oppressed. New York: The Continuum Publishing Company.

Garfat, T. (Ed.). (2003). A child and youth care approach to working with families. Binghamton, NY: The Haworth Press, Inc.

Gergen, K. (1994). Realities and relationships: Soundings in social construction. Cambridge, MA: Harvard University Press.

Gergen, K. (2009). Relational being: Beyond self and community. New York: Oxford University Press.

Gharabaghi, K. (2008). Contextual dialectics in relational work with youth. Relational Child and Youth Care Practice, 21(2), 5-9.

Harper, D. (2000). Reimagining visual methods: Galileo to neuromancer. In N. Denzin \& Y. Lincoln (Eds.), Handbook of qualitative research (2nd ed., pp. 717-732). Thousand Oaks, CA: SAGE.

Hillman, J. (1965/1997). Suicide and the soul. Putnam, CT: Spring Publications, Inc.

Hoskins, M. L. (1999). Worlds apart and lives together: Developing cultural attunement. Child and Youth Care Forum, 28(2), 73-85.

Hoskins, M., \& Artz, S. (2004). Working relationally with girls: Complex lives/complex identities. Binghamton, NY: The Haworth Press, Inc. 
International Journal of Child, Youth and Family Studies (2012) 1: 20-45

Krueger, M. (1994). Framing child and youth care in moments of rhythm, presence, meaning, and atmosphere. Child and Youth Care Forum, 23(4), 223-229.

Kvale, S. (1996). InterViews: An introduction to qualitative research interviewing. Thousand Oaks, CA: SAGE.

Kwee, A. (2007). Constructing addiction from experience and context: Peele and Brodsky’s “Love and Addiction” revisited. Sexual Addiction and Compulsivity, 14(3), 221-237.

Lambert, O., \& Charles. G. (2008). Crystal meth: Gaps and knowledge. Relational Child and Youth Care Practice, 21(2), 10-19.

Lee, J-A., \& de Finney, S. (2004). Using popular theatre for engaging racialized minority girls in exploring questions of identity and belonging. In M. Hoskins \& S. Artz (Eds.), Working relationally with girls: Complex lives/complex identities (pp. 95-118). Binghamton, NY: The Haworth Press, Inc.

Leitch, R. (2006). Limitations of language: Developing arts-based creative narrative in stories of teachers’ identities. Teachers and Teaching: Theory and Practice, 12(5), 549-569.

Lende, D., Leonard, T., Sterk, C., \& Elifson, K. (2007). Functional methamphetamine use: The insider's perspective. Addiction, Research and Theory, 15(5), 465-477.

Maier, H. (1991). An exploration of the substance of child and youth care practice. Child and Youth Care Forum, 20(6), 393-411.

McKnight, J. (1995). The careless society: Community and its counterfeits. New York: Basic Books.

Moss, P., \& Petrie, P. (2002). From children's services to children's spaces: Public policy, children, and childhood. New York: RoutledgeFalmer.

Nakkula, M., \& Ravitch, S. (1998). Matters of interpretation: Reciprocal transformation in therapeutic and developmental relationships with youth. San Francisco, CA: Jossey-Bass Publishers.

Neuhaus, C. (1993). The disease controversy revisited: An ontologic perspective. Journal of Drug Issues, 23(3), n.p.

Newbury, J., \& Hoskins, M. (2008). A meaningful method: Research with girls who use crystal methamphetamine. Child and Youth Care Forum, 37(5/6), 227-240. 
International Journal of Child, Youth and Family Studies (2012) 1: 20-45

Newbury, J., \& Hoskins, M. (2010). Girls are so complicated! Re-imagining addiction support in context. Canadian Journal of Counseling, 44(1), 15-33.

Newbury, J. (2010). Contextualizing child and youth care: Striving for socially just practice. Relational Child and Youth Care Practice, 22(4), 20-34.

Partnership for a Drugfree America. (2007). [online] New York: Author. Retrieved November 10, 2007, from www.drugfree.org/Portal/Drug_Guide/Methamphetamine

Peavy, V. (2004). SocioDynamic counselling: A practical approach to meaning making. Chagrin Falls, OH: Taos Institute.

Reynolds, V. (2002). Weaving threads of belonging: Cultural witnessing groups. Journal of Child and Youth Care, 15(3), 89-105.

Richardson, C. (2005). Steps to dignity and decolonization: Family group conferencing with Aboriginal families. Restorative Directions, 2(1).

Riley, R., \& Manias, E. (2004). The use of photography in clinical nursing practice and research: A literature review. Journal of Advanced Nursing, 48(4), 397-405.

Roche, D. (1976). Justice not charity: A new global ethic for Canada. Toronto: McClelland and Stewart Ltd.

Rojano, R. (2007). The practice of community family therapy. In E. Aldarondo (Ed.), Advancing social justice through clinical practice (pp. 245-264). Mahwah, NJ: Lawrence Erlbaum Associates, Publishers.

Rose, N. (1998). Inventing our selves: Psychology, power, and personhood. New York: Cambridge University Press.

Saul, D. (Ed.). (2005). Western Canadian summit on methamphetamine: Bringing together practitioners, policy makers, and researchers (Consensus panel report). Vancouver, BC: Vancouver Coastal Health.

Szasz. T. (2002). “Diagnosing” behaviour: Cui bono? In J. D. Raskin \& S. K. Bridges (Eds.), Studies in meaning: Exploring constructivist psychology (pp. 169-179). New York: Pace University Press.

Taylor, D., Segal, D., \& Harper, N. (2010). The ecology of adventure therapy: An integral systems approach to therapeutic change. Ecopsychology, 2(2), 77-83.

Truan, F. (1993). Addiction as a social construction: A post-empirical view. The Journal of Psychology, 127(5), 489-499. 
International Journal of Child, Youth and Family Studies (2012) 1: 20-45

Wade, A. (2007). Despair, resistance, hope: Response-based therapy with victims of violence. In C. Flaskas, I. McCarthy, \& J. Sheehan (Eds.), Hope and despair in narrative and family therapy: Adversity, forgiveness and reconciliation (pp. 63-74). New York: Routledge/Taylor \& Francis Group.

Walter Goodhart, F., Hsu, J., Baek, J., Coleman, A., Maresca, F., \& Miller, M. (2006). A view through a different lens: Photovoice as a tool for student advocacy. Journal of American College Health, 55(1), 53-57.

Wang, C., Morrel-Samuels, S., Hutchison, P., Bell, L., \& Pestronk, R. (2004). Flint Photovoice: Community building among youths, adults, and policymakers. American Journal of Public Health, 94(6), 911-913.

White, J. (2007). Knowing, doing, and being in context: A praxis-oriented approach to Child and Youth Care. Child and Youth Care Forum, 36(5/6), 225-244.

Wilson, N., Dasho, S., Martin, A., Wallerstein, N., Wang, C., \& Minkler, M. (2007). Engaging young adolescents in social action through photovoice: The Youth Empowerment Strategies (YES!) Project. Journal of Early Adolescence, 27(2), 241-261. 